\title{
Diaphragmatic Eventration : Review of Current Knowledge, Diagnostic, and Management Options
}

\author{
Joanna de Andrade Cordeiro ${ }^{\mathbf{1}}$; Ana Karla Almeida ${ }^{\mathbf{1}}$; Senival Alves de Oliveira \\ Júnior $^{1}$; Barbara Monitchelly Fernandes ${ }^{1}$; Amalia Cinthia Meneses Rego ${ }^{2}$; Irami \\ Araújo-Filho ${ }^{3}$; Aldo Cunha Medeiros ${ }^{4}$. \\ ${ }^{1}$ Graduating Medical University RN-Laureate International Universities \\ ${ }^{2}$ Director of the School of Health University RN- Laureate International Universities \\ ${ }^{3}$ Full Professor of Department of Surgery at the Federal University of Rio Grande do Norte \\ ${ }^{4}$ Full professor of Department of Surgery at the Federal University of Rio Grande do Norte \\ irami.filho@uol.com.br/irami.filho@gmail.com
}

\begin{abstract}
The diaphragmatic eventration [ED] is a rare pathology, commonly asymptomatic, but can result in dyspnea and recurrent respiratory infections. Can be caused can a congenital defect or be acquired by phrenic nerve injury. Your diagnosis occurs primarily through the visualization of the elevation of the diaphragmatic dome affected on chest x-rays applied at random. Your management depends on the clinical symptoms, which if present, surgical treatment and minimally invasive techniques the procedure of choice.
\end{abstract}

Keywords: Diaphragmatic eventration, congenital abnormalities, congenital diaphragmatic defect, diaphragm, musculoskeletal abnormalities, respiratory system abnormalities.

\section{INTRODUCTION}

The diaphragmatic eventration is the partial or total replacement of the diaphragm muscle fibroblastic tissue, causing the displacement of the hemidiaphragm affected to the chest by becoming weakened. Despite this, the diaphragm maintains its continuity and continuity of its annexes to the costal margin [1].

This substitution will result in a very thin membrane and compliant, which will lead to a decrease of the movements and even paradoxical movement, causing a poor lung expansion and decreased blood flow, generating a hypoxia-mediated vasoconstriction. This elevation of the diaphragmatic dome to the chest also allows the protrusion of abdominal contents to the thoracic cavity. These changes justify the prejudice in the vents and the main clinical manifestations [2].

ED affects less than $0.05 \%$ of the population, both children as adults, is more common in males. This abnormal elevation of the diaphragm can affect one or both hemidiaphragms, is more common, the unilateral involvement and the left hemidiaphragm [3].

Can be caused by a congenital defect or acquired. When congenital, can be isolated or associated with other congenital anomalies, have partial or diffuse involvement of the hemidiaphragm, and be a consequence of a defect in the diaphragm or muscle defect due to the absence of the phrenic nerve [4]. However, the most common etiology is acquired, which is caused by phrenic nerve injury during a traumatic birth or thoracic surgery for the correction of congenital heart disease. In this case, the central tendon is normal and the diaphragm muscle is developed of atrophic form. So the phrenic nerve is small and both sides are affected equally [5,6].

The main differential diagnosis is the unilateral phrenic nerve paralysis that causes progressive atrophy of the muscle. For some authors is known as diaphragmatic eventration. Other diseases that also make differential diagnosis are subdiafragmáticas or diaphragmatic masses and pleural effusion subpulmonary [7].

The ED is usually asymptomatic but may be the cause of a progressive dyspnea and frequent respiratory infections and surgery to fix is indicated in patients who are symptomatic [4]. 


\section{GOALS}

We seek to review the main features of diaphragmatic eventration (ED) about its definition, etiology, pathophysiology, clinical presentation, diagnosis and therapeutic options currently available to that entity.

\section{Materials ANd Methods}

It is a descriptive review of literature in databases, Pubmed, Scopus, Scielo and Lilacs, using as descriptors diaphragmatic "diaphragmatic eventration", "congenital abnormalities", "congenital diaphragmatic defect", "diaphragm", "musculoskeletal abnormalities", "respiratory system abnormalities". We included english and portuguese language articles, published between 1999 and 2015 that, who portrayed ED. Initially, 18 articles were selected, of which only 15 were used in this review.

\section{Anatomy And Physiology of The Diaphragm Muscle}

The most important respiratory muscle is the diaphragm muscle. This is the boundary between the chest cavity from the abdominal cavity pressure negative and positive pressure. It is essential for the normal functioning of respiratory mechanics because its contraction promotes air circulation in the lungs, through the reduction of the pleural pressure and expansion of the rib cage to move so when injured, impairs ventilation and oxygenation [6-8].

The diaphragm is made up of two components: the central tendon, contractile not; and muscle groups, responsible for their contraction. The muscle groups are divided in costal and crural. Leaflets diaphragmatics formed by the costal muscle group are thin and its contraction flattens the diaphragm and reduces the ribs. The flyers already diaphragmatics formed by the femoral muscle group are thicker and contribute less to the displacement of the diaphragm [6].

Both muscle groups are innervated by phrenic nerve that originates in the branches of $\mathrm{C} 3, \mathrm{C} 4$ and $\mathrm{C} 5$ and is part of the central diaphragm. The vascular supply is from the phrenic artery below the diaphragm and the pericardiofrênicas arteries above the diaphragm [6,7].

\section{Diagnosis}

The clinical presentation of diaphragmatic eventration has a variable spectrum, depending on the type of eventration (whether total or partial) and the greater or lesser elevation and function of the diaphragmatic dome. In adults, the most common form of presentation is asymptomatic. This occurs when the defects are small, the diaphragm is little high and is associated with the preservation of some muscle function and without compromise of the contralateral were, that compensates for the affected side [9].

The forms of intermediary involvement may present with respiratory distress, which represents the most common clinical manifestation: orthopnea, recurrent respiratory infections, bad weight progression and intolerance to stress. Newborns may be with a syndrome of potentially fatal acute respiratory difficulty, which can complicate with mediastinal deviation and pulmonary hypoplasia. Older children and adults may complain of digestive symptoms, such as abdominal pain, vomiting and flatulence [2].

The presence of associated factors, such as pulmonary hypoplasia in the affected side, mediastinal deviation and contralateral hypoplasia; compression of pulmonary atelectasis base and poor drainage; promote the development of bronchopneumonia and increase respiratory distress [8]

The diaphragmatic eventration be predominantly asymptomatic, it is usually discovered accidentally by a chest $\mathrm{x}$-ray [9]. In suspected cases, must be requested a chest $\mathrm{x}$-ray in the posterior-anterior and lateral impact and assess the presence of elevation and narrowing of the dome of the hemidiaphragm affected, but not interrupted on abdominal viscera, being higher than the contralateral hemidiaphragm, in at least one intercostal space when located on the left and in at least two intercostal spaces when located on the right [8]. The lifting area corresponds to the weakened area or fibrotic of hemidiaphragm, moving to the thorax and justifying this respiratory distress [2].

The confirmation must be done through a chest $\mathrm{x}$-ray, ultrasonography showing diaphragmatic movement minimal or paradoxical (the diaphragm muscle rises on inspiration and lower at expiration in relation to the abdominal cavity). If necessary, you can forward to surgery and show directly the defect $[10,11]$. 
For asymptomatic patients, an additional assessment is required. However, those patients with dyspnea of exertion or when it is not clear if the diagnosis is ED, can make lung function tests, that show often more or less significant decrease of vital capacity and forced expiratory volume. If intrathoracic diseases or are suspected, intra-abdominal a CT scan should be obtained [2, 7-10].

ED bilaterally is extremely rare, but when present, unlike the unilateral eventração, almost always is associated with significant respiratory impairment and invariably is manifested in the neonatal period [10].

\section{Treatment}

The diaphragmatic eventration is responsible for significant morbidity in children and in cases of severe disease, surgical intervention may be required [8]. The management of this pathology depends on the degree of respiratory distress. In asymptomatic cases and with mild respiratory distress, you must do just the support treatment with supplemental oxygen. ${ }^{1}$ Justified the expectant attitude under periodic clinical surveillance, on the good spontaneous evolution of ED in these cases [2].

The moment the day of surgery depends on the oppression caused by the diaphragmatic eventration in the ipsilateral lung and respiratory discomfort for the patient. In cases of serious and persistent respiratory distress or who need mechanical ventilation, you must do the surgical fixation of the diaphragm, which is surgical procedure of choice in cases of diaphragmatic eventration [1].

This procedure aims at increasing the thoracic volume and vital capacity and reduce the paradoxical movement of the diaphragm, solving the problem, minimizing the clinical manifestations and making more efficient ventilation [2, 12-14].

Traditionally, this procedure is performed through a posterolateral incision with thoracotomy or laparotomy. Recently, several cases have been published describing minimally invasive techniques of thoracoscopic and laparoscopic approach. Advances in endoscopic surgery has allowed the diaphragmatic eventration is treated quickly and safely and effectively for the patient [3].

Thoracoscopic approach is performed with the patient in lateral decubitus and the surgeon in front of the patient with television behind. Are held three openings: one of $5 \mathrm{~mm}$ in the sixth intercostal space in the midaxillary line, to the sorry pass; another break in the seventh intercostal space in midaxillary line and the other opening is the sixth intercostal space in the posterior axillary line or eighth intercostal space in midaxillary line. An artificial pneumothorax with $4-6 \mathrm{mmHg}$ using carbon dioxide $\left(\mathrm{CO}_{2}\right)$ is made to show the operation [4].

Already the laparoscopic technique, the patient is in the supine position and the surgeon between your legs. The first trocar is subumbilical. After inflating the abdomen with $\mathrm{CO}_{2}$, is held an opening in the midline between the xiphoid appendix and the navel and another opening in the upper quadrant of the abdomen $[4,5]$.

These new procedures avoid the short and long-term morbidity associated with open thoracotomy, such as thoracic dystrophy and scoliosis, have minimal incisions and result in decreased pain, short period of hospitalization, rapid return normal daily activities and the specific treatment of the exact problem [3].

However, the application also has disadvantages for diaphragmatic be dependent on the experience of the surgeon, as less depth perception, decreased range of motion, accuracy and ergonomics engaged uncomfortable; In addition to the effects of $\mathrm{CO} 2$ Insufflation, causing hypoxia, hypercapnia and hemodynamic changes $[4,8,15]$.

The surgical reoperation is indicated in cases where there is no significant improvement of the position of the diaphragm against the chest during follow-up for 4-6 months, associated with recurrence of respiratory tract infections. In addition to increased elevation of the diaphragm during follow-up despite the surgery [3-5].

\section{Conclusion}

Therefore, the diaphragmatic eventration is a rare entity but that all surgeons should be aware because it has a painting predominantly asymptomatic but can be associated with respiratory symptoms is important. Surgical treatment depends on the degree of respiratory distress and, currently, we have the minimally invasive techniques that revolutionized the surgical approach comes to correct this defect. Thoracoscopic and laparoscopic approach are viable options have all the advantages of minimally invasive surgery, compared to the old approach by thoracotomy and laparotomy. 


\section{REFERENCES}

[1] Ghribi A, Bouden A, Braiki M, Jabloun A, Sghairoun N, Gasmi M, Hamzaoui M. Diaphragmatic eventration in children. Tunis Med. 2015 Feb;93(2):76-8.

[2] Saha S, Bal HS, Sen S. Spontaneous rupture of a congenital diaphragmatic eventration in an infant. BMJ Case Rep. 2015 May 14;2015.

[3] Miyano G, Yamoto M, Kaneshiro M, Miyake H, Morita K, Nouso H, Koyama M, Okawada M, Doi T, Koga H, Fukumoto K, Lane GJ, Yamataka A, Urushihara N. Diaphragmatic eventration in children: laparoscopy versus thoracoscopic plication. J Laparoendosc Adv Surg Tech A. 2015 Apr;25(4):331-4.

[4] Ali Shah SZ, Khan SA, Bilal A, Ahmad M, Muhammad G, Khan K, Khan MA. Eventration of diaphragm in adults: eleven years experience. $J$ Ayub Med Coll Abbottabad. 2014 Oct-Dec;26(4):459-62.

[5] Camerano ME, Piccolo A, Matarasso M. [Diaphragmatic eventration]. Arch Argent Pediatr. 2014 Dec;112(6):577-8.

[6] Olusoji OO, Thomas MO, Ogunleye EO, Adekola OO. Eventration of the diaphragm-case reports and review of the literature. Nig Q J Hosp Med. 2013 Apr-Jun;23(2):142-4.

[7] Wu HH, Chen CH, Chang H, Liu HC, Hung TT, Lee SY. A preliminary report on the feasibility of single-port thoracoscopic surgery for diaphragm plication in the treatment of diaphragm eventration. J Cardiothorac Surg. 2013 Dec 5;8:224.

[8] Nason LK, Walker CM, McNeeley MF, Burivong W, Fligner CL, Godwin JD. Imaging of the diaphragm: anatomy and function. Radiographics. 2012 Mar-Apr;32(2):E51-70

[9] Sandstrom CK, Stern EJ. Diaphragmatic hernias: a spectrum of radiographic appearances. Curr Probl Diagn Radiol. 2011 May-Jun;40(3):95-115.

[10] León-Atance P, Martínez-Hernández NJ, Milla-Saba AM, Roca-Fernández J.Diseases of the diaphragm. Arch Bronconeumol. 2011;47 Suppl 8:37-40.

[11] Maish MS. The diaphragm. Surg Clin North Am. 2010 Oct;90(5):955-68.

[12] Le Pimpec-Barthes F, Brian E, Vlas C, Gonzalez-Bermejo J, Bagan P, Badia A, Riquet M, Similowski T. [Surgical treatment of diaphragmatic eventrations andparalyses. Rev Mal Respir. 2010 Jun;27(6):565-78.

[13] Groth SS, Andrade RS. Diaphragm plication for eventration or paralysis: a review of the literature. Ann Thorac Surg. 2010 Jun;89(6):S2146-50.

[14] Groth SS, Andrade RS. Diaphragmatic eventration. Thorac Surg Clin. 2009 Nov;19(4):511-9.

[15] Eren S, Ceviz N, Alper F. Congenital diaphragmatic eventration as a cause of anterior mediastinal mass in the children: imaging modalities and literature review. Eur J Radiol. 2004 Jul;51(1):85-90.

\section{AUTHORS' BIOGRAPHY}

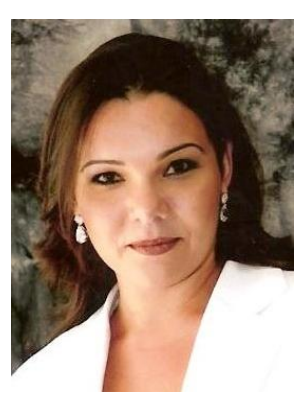

Amalia Cinthia Meneses Rego, Has a PhD in Health Sciences, Federal University of Rio Grande do Norte (2010), Specialization in Clinical Analysis from the Federal University of Rio Grande do Norte (2009), Specialization in Laboratory Hematology (2011) and Specialization in Microbiology Clinical and Laboratory Potiguar University (2011). Director of the School of Health, University Potiguar. Permanent faculty of the Graduate Program in Biotechnology / UNP. Coordinator of Institutional Programs PIBIC / CNPq and PIBITI / CNPq at the University Potiguar. Develops research activities with the Multidisciplinary Laboratory for Research of Research Base in Experimental 
Surgery Prof. Clovis Sarinho / UFRN and coordinator of the Multidisciplinary Research Group Experimental / UNP Surgery. He has experience in Experimental Surgery, Haematology, Biochemistry, Immunology and Microbiology. Currently works with research in the following areas: wound healing and statins, biodistribution, radioisotopes, infection, Herbal, etc.

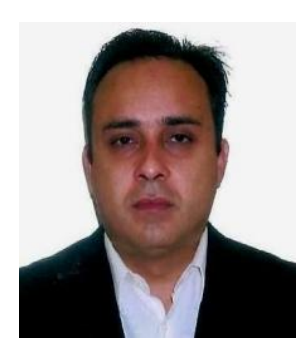

Irami Araújo-Filho, Graduated in Medicine from the Federal University of Rio Grande do Norte (2000), Master of Health Sciences (2005) and PhD in Health Sciences, Federal University of Rio Grande do Norte (2007). He is currently Full Professor of Surgical Technique of the Department of Surgery at the Federal University of Rio Grande do Norte, Member of the Brazilian College of Surgeons, Master of the Chapter of the Brazilian College of Surgeons in Rio Grande do Norte, Brazilian College of Titular Member Digestive surgery, Member of the Panamerican Trauma Society, Member of the Brazilian Society for the Development of Research in surgery, Vice-coordinator of the Research Base in Experimental surgery Prof. Clovis Sarinho, Director of Education, Research and extension at the University Hospital Onofre Lopes (HUOL) of the Federal University of Rio Grande do Norte, Preceptor of Medical Residency in General HUOL Surgery and Vice President of the Regional RN of the Brazilian Society for Development of Research in Surgery. Has experience in the area of Medicine, with emphasis in General Surgery, Gastroenterology and Oncology, acting on the following topics: infection in surgery, intercurrent factors in wound healing, biodistribution of radionuclide. 